\title{
Preferred structures in large-scale circulation and the effect of doubling greenhouse gas concentration in HadCM3
}

Article

Published Version

Hannachi, A. and Turner, A. G. (2008) Preferred structures in large-scale circulation and the effect of doubling greenhouse gas concentration in HadCM3. Quarterly Journal of the Royal Meteorological Society, 134 (631). pp. 469-480. ISSN 1477870X doi: https://doi.org/10.1002/qj.236 Available at https://centaur.reading.ac.uk/1149/

It is advisable to refer to the publisher's version if you intend to cite from the work. See Guidance on citing.

Published version at: http://dx.doi.org/doi:10.1002/qj.236

To link to this article DOI: http://dx.doi.org/10.1002/qj.236

Publisher: Royal Meteorological Society

All outputs in CentAUR are protected by Intellectual Property Rights law, including copyright law. Copyright and IPR is retained by the creators or other copyright holders. Terms and conditions for use of this material are defined in the End User Agreement.

www.reading.ac.uk/centaur 
Central Archive at the University of Reading

Reading's research outputs online 


\title{
Preferred structures in large-scale circulation and the effect of doubling greenhouse gas concentration in HadCM3
}

\author{
A. Hannachi ${ }^{\mathrm{a}, \mathrm{b} *}$ and A. G. Turner ${ }^{\mathrm{a}}$ \\ a Department of Meteorology, University of Reading, UK \\ b Department of Meteorology, KA University, Saudi Arabia
}

\begin{abstract}
Preferred structures in the surface pressure variability are investigated in and compared between two 100year simulations of the Hadley Centre climate model HadCM3. In the first (control) simulation, the model is forced with pre-industrial carbon dioxide concentration $\left(1 \times \mathrm{CO}_{2}\right)$ and in the second simulation the model is forced with doubled $\mathrm{CO}_{2}$ concentration $\left(2 \times \mathrm{CO}_{2}\right)$. Daily winter (December-January-February) surface pressures over the Northern Hemisphere are analysed. The identification of preferred patterns is addressed using multivariate mixture models. For the control simulation, two significant flow regimes are obtained at $5 \%$ and $2.5 \%$ significance levels within the state space spanned by the leading two principal components. They show a high pressure centre over the North Pacific/Aleutian Islands associated with a low pressure centre over the North Atlantic, and its reverse. For the $2 \times \mathrm{CO}_{2}$ simulation, no such behaviour is obtained. At higher-dimensional state space, flow patterns are obtained from both simulations. They are found to be significant at the $1 \%$ level for the control simulation and at the $2.5 \%$ level for the $2 \times \mathrm{CO}_{2}$ simulation. Hence under $\mathrm{CO}_{2}$ doubling, regime behaviour in the large-scale wave dynamics weakens. Doubling greenhouse gas concentration affects both the frequency of occurrence of regimes and also the pattern structures. The less frequent regime becomes amplified and the more frequent regime weakens. The largest change is observed over the Pacific where a significant deepening of the Aleutian low is obtained under $\mathrm{CO}_{2}$ doubling. Copyright (c) 2008 Royal Meteorological Society
\end{abstract}

KEY WORDS seasonality; rotated EOFs; carbon dioxide; climate change

Received 3 March 2007; Revised 12 February 2008; Accepted 18 February 2008

\section{Introduction}

Climate models provide an important mathematical tool to simulate and understand climate variability. They are extensively used in most meteorological research centres to analyse climate variability, understand physical mechanisms, and project future climate, in addition to various other purposes. Differences between various models and also between models and observations or reanalyses are expected to arise because of differences in model resolutions, physical parametrizations (e.g. the cloud scheme), and also uncertainty/complexity in the climate system. A measure of the performance of any climate model is quite often given by how far the model can reproduce the observed behaviour from various aspects. For instance, the climatology of the model, the storm-track position and strength, and various teleconnections are examples of prognostic tools used to validate the model. These tools refer to the mean behaviour of the probability distribution of the climate system.

Now because climate is the result of complex nonlinear interactions between many degrees of freedom, the wisdom is that as well as linear aspects relating to these diagnostics, nonlinear aspects also have to be

* Correspondence to: A. Hannachi, Department of Meteorology, King Abdulaziz University, PO Box 80208, Jeddah 21589, Saudi Arabia. E-mail: A.Hannachi@reading.ac.uk used for model validation. One such particular aspect of nonlinearity concerns the regime behaviour of the largescale tropospheric flow. This is particularly important for climate change studies where it is argued that climate change can act to change the frequency of naturally occurring circulation regimes (Palmer, 1993, 1999; Corti et al., 1999; Christiansen, 2003). Hsu and Zwiers (2001) and Stephenson et al. (2004) describe the robustness of previous regime studies. For example, changes in the Northern Hemispheric $(\mathrm{NH})$ winter climate can be understood in terms of changes in the preferred planetary flow regimes. Note that many scientists would regard preferred large-scale flows as representing some aspects of (quasi)nonlinearity. This subtle issue is not discussed here, and the reader is referred to Hannachi (2007; referred to as H07 below) for further details and references.

Various investigations looked at the effect of changes in greenhouse gas concentration on recurrent circulation regimes. Hsu and Zwiers (2001), for example, used a (non-objective) clustering method to analyse changes in $\mathrm{NH}$ as well as sectorial recurrent regimes under increasing greenhouse gas and aerosol forcing using a model from the Canadian Climate Center for modeling and analysis (CCCma). Their analysis indicates a change in the frequencies of occurrence of sectorial recurrent regimes, but no such evidence was obtained for the hemisphere. Solman and Le Treut (2006) analysed changes in 
sectorial circulation regimes in the Southern Hemisphere using the Institut Pierre Simon Laplace coupled model (IPSL-CM2) in a transient simulation with a gradual increase in greenhouse forcing. They find no significant change in regime behaviour regarding intraseasonal and synoptic-scale variation. Kageyama et al. (1999) looked at sectorial circulation regimes in the present day, inception of the last glaciation (115 Ky before the present) and last glacial maximum ( $21 \mathrm{Ky}$ before the present) using the Laboratoire de Météorologie Dynamique general ciculation model. They found similar regimes but with different population size.

The recent analysis of $\mathrm{H} 07$ shows regime behaviour in the winter $\mathrm{NH}$ geopotential height fields. The analysis was based on the available National Center for Environmental Prediction and the National Centre for Atmospheric Research (NCEP/NCAR) reanalyses. A mixture model was used for the probability density function (p.d.f.) of winter $500 \mathrm{mb}$ geopotential heights. The p.d.f. in this case is written as a finite weighted average of multivariate Gaussian p.d.f.s. The number of components is obtained using tools from order statistics, and the individual components of the multivariate Gaussian mixture are obtained using the expectation-maximization (EM) algorithm (Everitt and Hand, 1981). Two highly significant regimes are found - a Pacific/North American (PNA) and the North Atlantic Oscillation (NAO) pattern and its reverse. To investigate the possibility of the global warming effect on the large-scale flow, the same analysis has been applied to two subsamples corresponding to pre- and post-1978. Two similar but not identical circulation regimes have also been found in each of the two periods, with stronger regime behaviour in the first period than in the second.

In this paper, we follow the methodology of H07 to analyse two 100-year model simulations, a control and a perturbed run, to study large-scale preferred flows using surface pressure (SP). The control simulation is forced with pre-industrial $\mathrm{CO}_{2}$ concentration $\left(1 \times \mathrm{CO}_{2}\right)$ whereas the perturbed run is forced with doubled $\mathrm{CO}_{2}$ concentration $\left(2 \times \mathrm{CO}_{2}\right)$. In section 2 , a brief description of the model data and the methodology is presented. The model variability, and comparison between the two simulations is provided in section 3. Section 4 presents the results of preferred flow structures in planetary wave dynamics in the two simulations. A summary and discussion are provided in the last section.

\section{Data and methodology}

\subsection{Model data}

The data considered here derive from two 100-year integrations of the fully coupled Hadley Centre climate model (HadCM3). The atmospheric component (HadAM3) is a version of the UK Met Office Unified Model for numerical weather prediction and climate, operating at a grid-point resolution of $3.75^{\circ}$ longitude $\times 2.5^{\circ}$ latitude. The atmospheric component features an improved radiation scheme over previous versions (Edwards and Slingo, 1996), and a land surface scheme of soil processes and exchanges of heat and moisture between the Earth's surface and the planetary boundary layer (Cox et al., 1999; Pope et al., 2000). The impact of improved parametrizations is particularly evident in the Tropics and also in $\mathrm{NH}$ midlatitudes, where the frequency of blocking events is much more realistic than in earlier versions, particularly in the Pacific (Pope et al., 2000). It has been shown by Pope et al. (2000) that the latest version of HadAM3 produces improvements in the mean climate and also compares well with observations. The coupled model HadCM3 is also shown by Gordon et al. (2000) to reproduce many aspects of the observed heat budget.

The standard vertical resolution in HadAM3 is 19 levels (L19), although 30 levels (L30) are used in this framework after Inness et al. (2001), who noted better representation of intraseasonal variability in tropical convection. Spencer and Slingo (2003) also determined that the increased vertical resolution improves the sensitivity of precipitation to sea surface temperature (SST) variation in the tropical Pacific, generating a more realistic downstream response of the Aleutian low/North Pacific region to the effects of the El Niño Southern Oscillation (ENSO). The ocean component is solved on 20 levels at a uniform $1.25^{\circ}$ resolution. Much improved over earlier coupled models, HadCM3 lacks any significant climate drift. Thus ocean surface heat flux adjustments are not required to counteract this. (As pointed out by one referee, the fact that the (standard) HadCM3 did not drift does not guarantee that the L30 model would not drift since changing the vertical resolution can change many aspects of model behaviour including climate sensitivity. However, we have not noticed any drift in any of the several 100-year runs.), even over multi-century integrations (Gordon et al., 2000).

Collins et al. (2001) examined the internal variability in HadCM3 in a long control simulation. The interdecadal variability of the model ocean in the Tropical Pacific, North Pacific and North Atlantic was found to be comparable to that from the real ocean. They also examined atmospheric extratropical variability. They found that the model simulates an Arctic Oscillation(AO)/NAO in the winter hemisphere, with spatial patterns consistent with NCEP/NCAR reanalyses, particularly in the Atlantic sector, with more teleconnection over the Pacific sector. Further on the extratropics, Pope et al. (2000) found that the model has realistic blocking amplitude and extent, possibly related to improvements in diabatic forcing over Indonesia, hence the importance of the Tropics for the extratropics. They also found an improved mean sea level pressure in most regions, reducing biases over the Northeast Pacific, North America, North Atlantic, and North Eurasia in winter and spring. They pointed out that this is consistent with good blocking over the North Atlantic and North Pacific.

Given the direct relevance of the Tropics to the extratropics, we also briefly discuss the tropical climate in the model. ENSO is also well represented in the model. 
Despite a cold bias in the central equatorial Pacific in common with many coupled models, HadCM3 represents some essential characteristics of ENSO. HadCM3 features strong SST variability in the eastern equatorial Pacific, in common with observations, however the centre of action is still located too far west, related to coupled biases in the low-level wind, precipitation and SST fields (Turner et al., 2005). Variability in both Niño-3 and Niño-4 indices is stronger than observed whilst the annual cycle in the east is too weak (Latif et al., 2001.) A fundamental characteristic of observed ENSO events is their phase locking to the seasonal cycle, i.e. the preference of El Niño/La Niña peaks to occur during boreal winter, and a variance minimum during spring. With L19, HadCM3 fails to represent this phase locking (Latif et al., 2001), however at L30 the seasonal cycle of variance has more in common with observed values (Turner et al., 2005). HadCM3 poorly represents the extension of the west Pacific warm pool prior to El Niño, thought necessary for El Niño development and related to synoptic time-scale westerly wind events near the surface. There is some indication of eastward propagation of subsurface heat content anomalies during ENSO (Latif et al., 2001), although the phenomenon is too regular both beneath and on the surface.

The data used in this paper consist of daily SP during boreal winter, i.e. December to February (DJF), north of $20^{\circ} \mathrm{N}$. Two 100-year simulations are used: a control run and a perturbed run. The control run corresponds to preindustrial (pre-1860) $\mathrm{CO}_{2}$ concentrations, i.e. $290 \mathrm{ppm}$ $\left(1 \times \mathrm{CO}_{2}\right)$. The perturbed climate-change experiment is forced by doubling $\mathrm{CO}_{2}$ concentration $\left(2 \times \mathrm{CO}_{2}\right)$, i.e. $580 \mathrm{ppm}$. The perturbed run was initialized from an existing 150-year $2 \times \mathrm{CO}_{2}$ run, prior to which $\mathrm{CO}_{2}$ had been ramped up at a rate of $1 \%$ year $^{-1}$ for 70 years. Thus the coupled atmosphere-ocean system may be regarded as in stable equilibrium.

\subsection{Methodology}

The estimation of the climate p.d.f. is a difficult and challenging problem. There are mainly two methods of p.d.f. estimation: parametric and non-parametric. In the non-parametric method, the p.d.f. is estimated using various smoothing procedures, such as the kernel method, and no p.d.f. family is required. In the parametric method, however, the p.d.f. is estimated from a specific family, e.g. a Gaussian distribution. Non-parametric methods require fixing the smoothing procedure and smoothing parameters. For example in kernel p.d.f. estimation, the kernel and the width (smoothing) parameter have to be chosen, and in general the results depend on this choice. Parametric methods on the other hand rely on the chosen family of distributions. The method used here, although parametric, does not rely on a particular family of distributions. The method is based on a general result, which states that any p.d.f. $f(\mathbf{x})$ can be decomposed as closely as desired by a weighted average, or a mixture of multivariate Gaussian density functions (Anderson and Moore, 1979), i.e.

$$
f(\mathbf{x})=\sum_{k=1}^{c} \alpha_{k} g_{k}\left(\mathbf{x}, \boldsymbol{\Sigma}_{k}, \boldsymbol{\mu}_{k}\right),
$$

where $\alpha_{1}, \ldots, \alpha_{c}$ are the $c$ mixing proportions of the mixture model and they satisfy

$$
0<\alpha_{k}<1, \text { for } k=1, \ldots, c, \text { and } \sum_{k=1}^{c} \alpha_{k}=1,
$$

and $\boldsymbol{\mu}_{k}$ and $\boldsymbol{\Sigma}_{k}$ are, respectively, the mean and the covariance matrix of the $k$ th (with $k=1, \ldots, c$ ) multivariate normal density function $g_{k}$ :

$$
\begin{aligned}
& g_{k}\left(\mathbf{x}, \boldsymbol{\Sigma}_{k}, \boldsymbol{\mu}_{k}\right) \\
& =(2 \pi)^{-d / 2}\left|\boldsymbol{\Sigma}_{k}\right|^{-1 / 2} \exp \left[-\frac{1}{2}\left(\mathbf{x}-\boldsymbol{\mu}_{k}\right)^{\mathrm{T}} \boldsymbol{\Sigma}_{k}^{-1}\left(\mathbf{x}-\boldsymbol{\mu}_{k}\right)\right],
\end{aligned}
$$

where $d$ is the state space dimension. Hannachi and O'Neill (2001) and H07 provide more details. The $\{c(d+1)(d+2)-2\} / 2$ unknown parameters of model (1) are obtained using the EM algorithm (Hannachi and O'Neill, 2001). The most difficult part of identifying model (1) is the number $c$ of components, which is obtained as in $\mathrm{H} 07$ using an argument from order statistics via Monte Carlo to construct confidence limits for the mixing proportions. In brief, to get confidence limits on the proportions $\alpha_{1}, \ldots, \alpha_{c}$, for a given number $c$ of multivariate Gaussian distributions, one hundred solutions maximizing the likelihood are obtained. Each solution is obtained via the EM algorithm using a different set of random initial conditions, and the obtained proportions sorted in decreasing order. Now if $\alpha_{1} \leq \alpha_{2} \leq$ $\ldots \leq \alpha_{c}$ are the true (unknown) mixing proportions of the mixture model with $c$ components, and if $\beta_{k}, 1 \leq k \leq c$, represent a realization of the true proportions, which are sorted as $\beta_{1} \leq \beta_{2} \leq \ldots \leq \beta_{c}$, then the principle of order statistics implies that $\beta_{k}$ is a realization of $\alpha_{k}, k=$ $1, \ldots, c$. These solutions provide therefore a probability distribution for the mixing coefficients, and approximate confidence limits on their means are then obtained at any chosen significance level $\alpha$. (see H07 for more details). The estimation is based on a normality assumption. This assumption is a simple and rough approximation that serves reasonably well the purpose of this research. A more precise approximation is beyond the scope of this paper. Only those components whose confidence intervals do not cross the zero value are considered significant. This procedure is then repeated for various values of $c$ starting from $c=2$ until the added component becomes non-significant. The method has been shown by $\mathrm{H} 07$ to be very successful in finding the different components of the mixture and also overcomes the difficulties encountered in previous studies related to the choice of an independent sample, and the effect of increasing the sample size and 
their effect on the number of Gaussian components (e.g. Hannachi and O’Neill, 2001; H07).

\section{Model variability}

\subsection{Climatology and seasonality}

This section analyses and compares the model variability between the two simulations. Comparison with results obtained using reanalyses from $\mathrm{H} 07$ will be mentioned when necessary. Figure 1 shows changes in winter mean SP climatology. The $\mathrm{CO}_{2}$ doubling clearly induces a pressure increase in midlatitudes and the subtropics and a decrease around Newfoundland and the Bering Strait. The dipole over the North Atlantic has a tendency to reinforce the positive phase of the NAO inducing more zonal flows reinforcing the storm track. This is also true for the northern part of the North Pacific.

Prior to analysing the model variability, the seasonal cycle is first computed, based on daily and monthly data, at three key locations: the North Atlantic $\left(60^{\circ} \mathrm{N}, 30^{\circ} \mathrm{W}\right)$, the North Pacific $\left(50^{\circ} \mathrm{N}, 180^{\circ}\right)$, and Siberia $\left(50^{\circ} \mathrm{N}\right.$, $\left.101.25^{\circ} \mathrm{E}\right)$. These locations correspond approximately to the northern centre of action of the NAO, the North Pacific Oscillation (NPO), and the Siberian high. The first two locations correspond respectively to the exits of the Pacific and Atlantic storm tracks, and are also the loci of frequent blocking flows. The Siberian high, in particular, has witnessed a dramatic decline in the last quarter of the century (Panagiotopoulos et al., 2005).
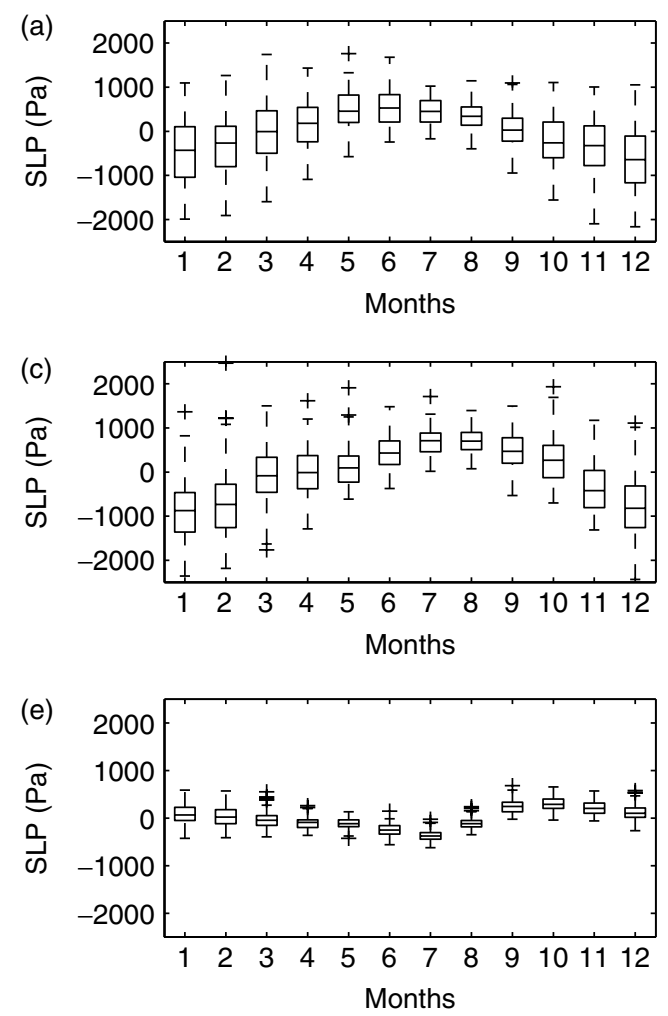

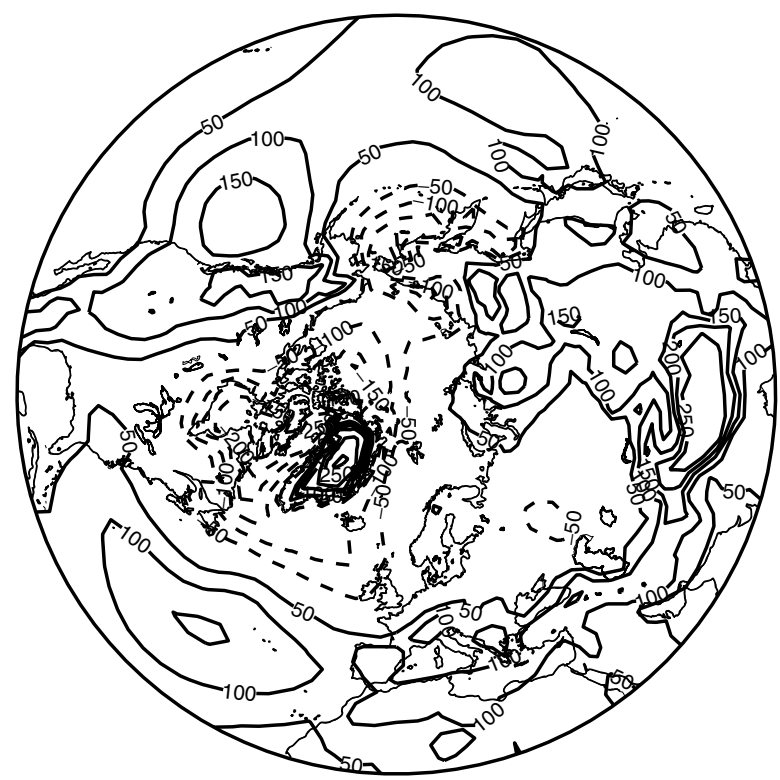

Figure 1. Changes in the daily winter (December-January-February) climatology of surface pressure between the $2 \times \mathrm{CO}_{2}$ and the control $\left(1 \times \mathrm{CO}_{2}\right)$ simulations. The contour interval is $50 \mathrm{~Pa}$.

Figure 2 shows the boxplot of monthly means of surface pressure anomalies (SPA), with respect to the long-term grand mean, for both simulations at the three locations mentioned above. There is a clear difference between the amplitude of the seasonal cycle for the North Atlantic and the North Pacific (Figure 2(a)-(d)) on one hand, and for Siberia (Figure 2(e,f)) on the other.
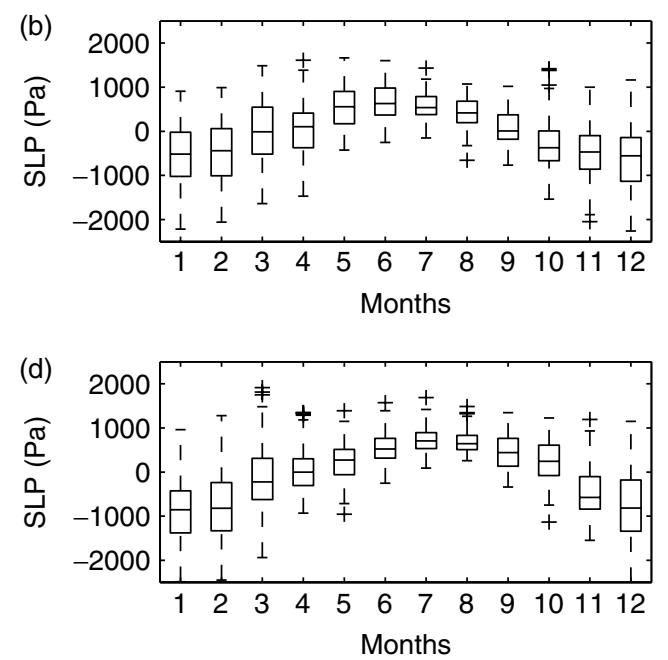

(f) 2000

Figure 2. Boxplot of monthly means of surface pressure anomalies, with respect to the long-term daily climatology, for (a,b) the North Atlantic, $(\mathrm{c}, \mathrm{d})$ the North Pacific, and (e,f) Siberia for both the control (a,c,e) and the $2 \times \mathrm{CO}_{2}(\mathrm{~b}, \mathrm{~d}, \mathrm{f})$ simulations. 
The amplitude of the seasonal cycle for the latter is substantially reduced. The seasonal cycle over the North Pacific is slightly stronger than that over the North Atlantic, with more and stronger outliers. In all cases there does not seem to be a shift in seasonality. For the North Atlantic, the median has gone slightly down in the $2 \times \mathrm{CO}_{2}$ experiment in winter (e.g. January and February) and slightly up in summer. Overall the variability, shown by the width of the box, has gone up slightly in spring whereas a reduction is obtained in autumn. An increase in the amplitude of anticyclones is obtained in April, July, and October. In the Pacific, the median has decreased in late winter and increased in early summer under doubled $\mathrm{CO}_{2}$, whereas the variability has increased in winter and decreased in summer/autumn. The seasonal cycle over Siberia is much weaker than that of the North Atlantic and the North Pacific. The small dip in summer (Figure 2(e,f)) can be distinguished from the maximum in the same period for the North Atlantic and the North Pacific (Figure 2(a)-(d)). A decrease in large anticyclonic activity is also clearly visible over Siberia, particularly in summertime.

\subsection{Modes of variability}

DJF SP daily anomalies, with respect to the (daily) mean seasonal cycle, are computed for both simulations. Empirical orthogonal functions (EOFs) of the data north of $20^{\circ} \mathrm{N}$ are then computed for each simulation. The data have been area-weighted prior to obtaining EOFs. Figure 3 shows the eigenvalue spectra of the associated covariance matrices. The vertical bars show the approximate $95 \%$ confidence limits of the eigenvalues, based on the rule of thumb of North et al. (1982), using a heuristic independent sample size of 400. This corresponds approximately to a decorrelation time of three weeks. The first two eigenvalues are non-degenerate. There is also a slight increase in explained variances of the $2 \times \mathrm{CO}_{2}$ leading EOFs compared to those of the control run.

Figure 4 shows the first three EOFs of the control (Figure $4(\mathrm{a}, \mathrm{c}, \mathrm{e}))$ and the $2 \times \mathrm{CO}_{2}$ (Figure $\left.4(\mathrm{~b}, \mathrm{~d}, \mathrm{f})\right)$ simulations. EOF1 of the control simulation (Figure 4(a)), explaining $10.6 \%$ of the total winter variance, shows a NAO whereas the $2 \times \mathrm{CO}_{2}$ EOF1 (Figure $4(\mathrm{c}), 11 \%$ ) is
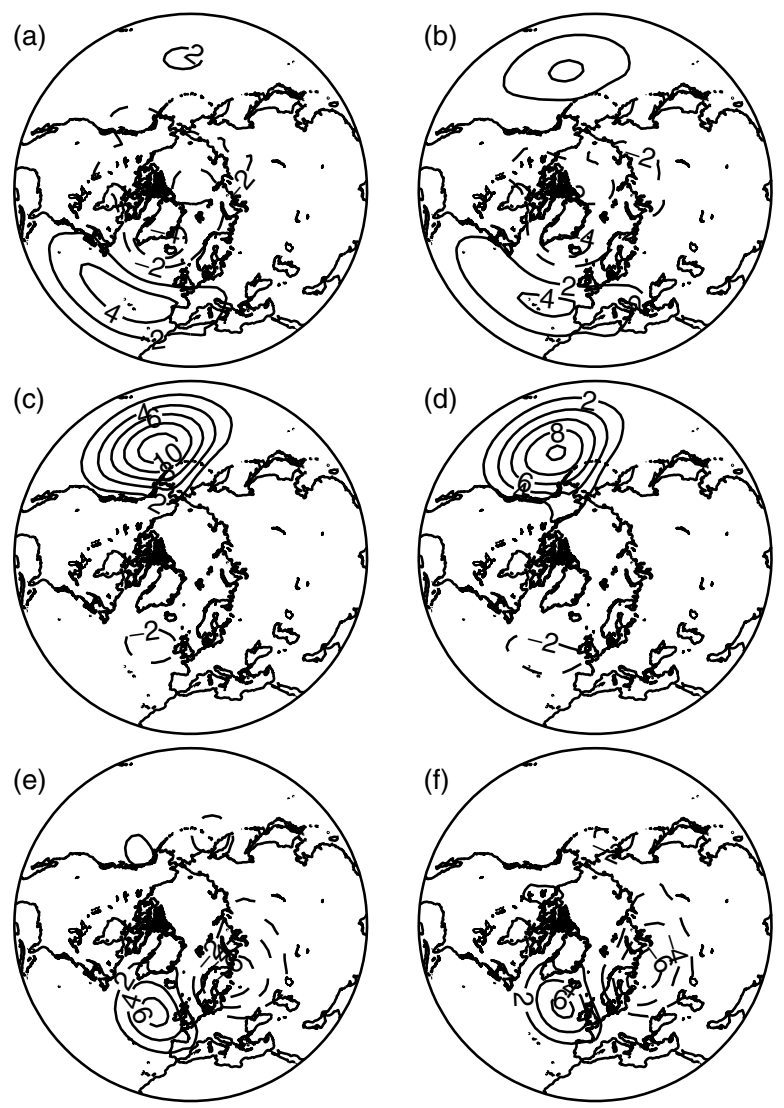

Figure 4. First three EOFs of the winter daily surface pressure anomalies for $(\mathrm{a}, \mathrm{c}, \mathrm{e})$ the control and $(\mathrm{b}, \mathrm{d}, \mathrm{f})$ the $2 \times \mathrm{CO}_{2}$ simulations. The patterns are multiplied by 100 .

more like the AO (Thompson and Wallace, 1998; Wallace and Thompson, 2002). EOF2 of the control simulation (Figure $4(\mathrm{c}), 7.9 \%$ ) is similar to that of the $2 \times \mathrm{CO}_{2}$ simulation (Figure 4(d), 8.6\%) and both show the NPO. The third EOF of each run shows the Scandinavian pattern but is degenerate. Most of the difference between the patterns of variability is captured by the leading pattern (Figure $4(\mathrm{a}, \mathrm{b})$ ). In the positive phase of the $2 \times \mathrm{CO}_{2} \mathrm{EOF} 1$ (Figure 4(b)), for example, there is a tendency to have a strengthening of both the North Atlantic and the North Pacific jets simultaneously. This certainly will bear on the nonlinear behaviour and/or the large-scale flow in
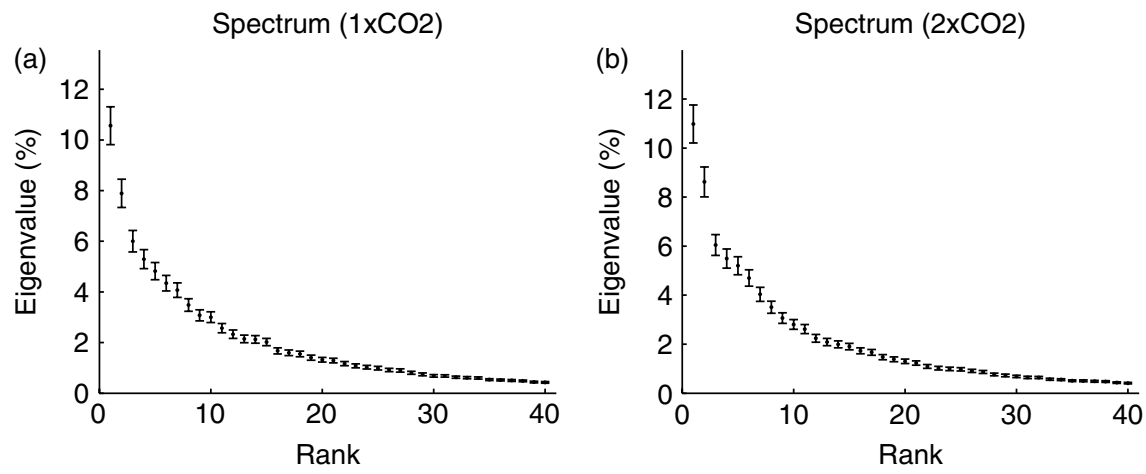

Figure 3. Spectra of the covariance matrices of the daily winter (DJF) surface pressure for (a) the control and (b) the $2 \times \mathrm{CO}_{2}$ simulations. The vertical bars show approximate $95 \%$ confidence intervals of the eigenvalues obtained using a heuristic independent sample size of 400 . 
the perturbed simulation, which is discussed in the next section.

\section{Preferred flow structures and the effect of $\mathrm{CO}_{2}$ doubling}

\subsection{Scatterplot exploration}

Preferred structures of the planetary wave dynamics are investigated here, in a similar way to $\mathrm{H} 07$, by seeking evidence for the existence of multiple flow regimes using multivariate Gaussian mixture models within the system state space defined by the surface pressure EOFs. Figure 5 shows a scatterplot matrix of the leading five principal components (PCs) for both the simulations. The diagonal in each case shows the histograms of individual PCs along with the normal fit. Some marginal distributions of the PCs, e.g. PC2 (Figure 5(a)), show some skewness. The marginal distributions, however, do not in general reflect the joint distribution, which can be inferred only by analysing the full scatter. For example, the scatterplot of (PC1,PC2) shows some departure from binormality, which will be quantified later. Another example is the scatterplot for (PC1,PC3), which shows
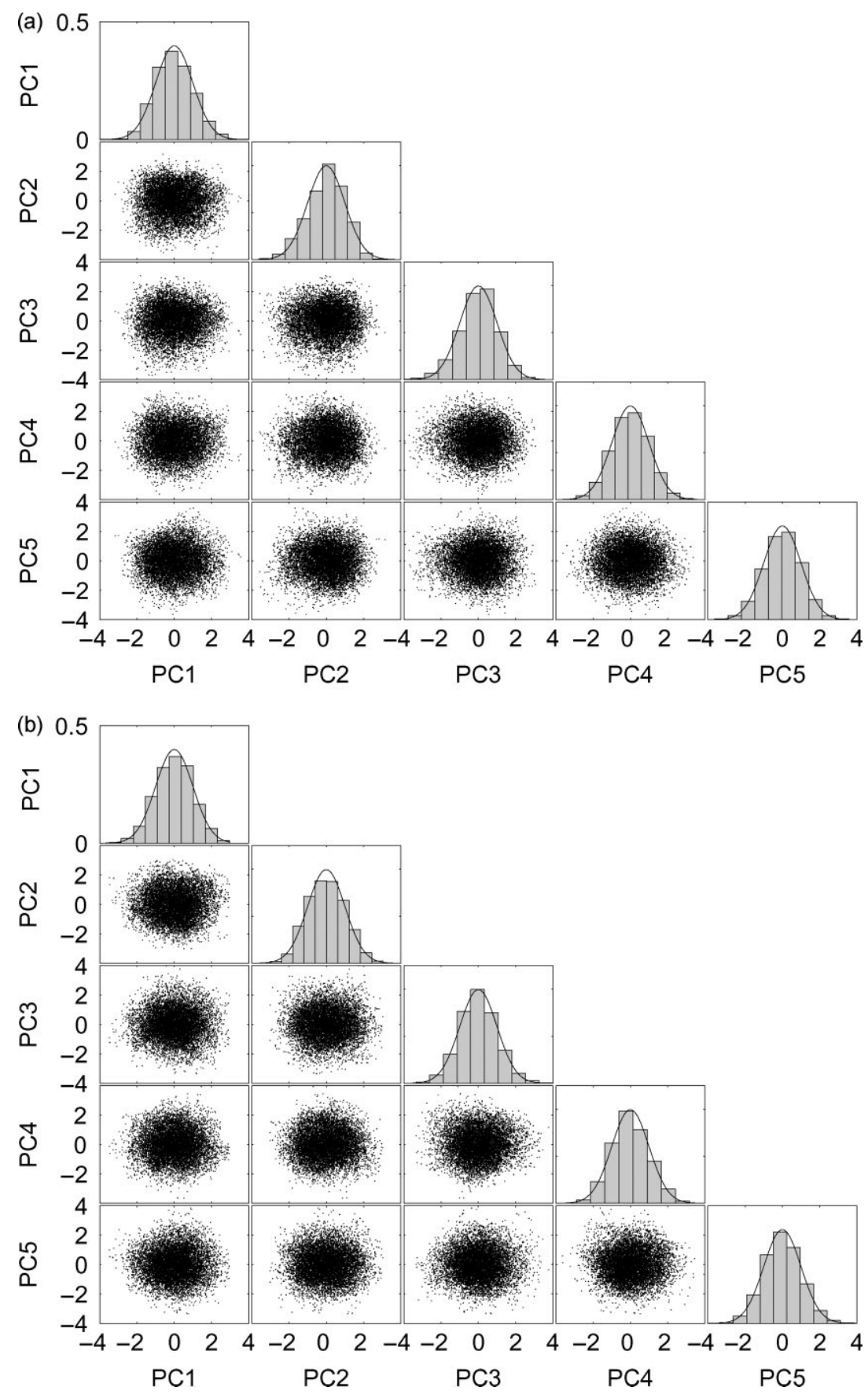

Figure 5. Scatterplot matrix of the first five PCs of daily winter surface pressure anomalies for (a) the control and (b) the $2 \times \mathrm{CO}_{2}$ simulations. The diagonals show the histograms and normal fitting for the individual PCs. 
some sort of a top-shaped distribution, a clear indication of departure from binormality. The high-density region in the (PC2,PC3) scatterplot, for example, is positioned towards the upper right corner, another signature of departure from bivariate Gaussian behaviour. There are of course scatterplots that look very binormal such as (PC3,PC4) and (PC4,PC5) clouds.

The skewness observed, e.g. in PC2 and PC3 (Figure 5(a)), is not evident from the same PCs in Figure 5(b). Using a two-sample Kolmogorov-Smirnov test, the individual PCs of the control run are found to be significantly (at the 5\% level) different from those of the $2 \times \mathrm{CO}_{2}$ run. This will automatically reflect on the scatterplots. For example, the non-Gaussian signature observed in the scatterplot of (PC1,PC3) in Figure 5(a) (top-shaped distribution) is reduced in Figure 5(b), where the highdensity region appears to be in the middle of the scatter (Figure 5(b)). This difference between the scatterplots is quantifed in the next section using the mixture model.

4.2. Analysis of preferred flow structures in the model simulations

The previous description is now quantified using mixture models with two and three bivariate Gaussians to model the joint probability distribution of $\mathrm{PC} 1$ and $\mathrm{PC} 2$ time series. The procedure developed in $\mathrm{H} 07$ and described briefly in section 2 is applied here. One hundred solutions, maximizing the likelihood, are selected. Each of them is obtained using many initial conditions by choosing the one with the largest likelihood. These solutions provide, after using order statistics, a sample of mixing proportions $\alpha_{1}$ and $\alpha_{2}$ when two bivariate Gaussians are used. Figure 6(a) shows the approximate $95 \%$ confidence interval of the mean of the mixing proportions when a two-component bivariate Gaussian mixture model is applied to the (PC1,PC2) scatter of the control run. Figure 6(b) is similar to Figure 6(a) except that a three bivariate Gaussian mixture model is applied. At the 5\% significance level, the (PC1,PC2) scatterplot clearly supports (at least) two components (Figure 6(a)). This is further supported by looking at the mixing proportions when three bivariate Gaussians are used (Figure 6(b)), where the third component is insignificant at the $5 \%$ significance level. The two obtained components are still significant at the $2.5 \%$ level but not at the $1 \%$ level (not shown). The same procedure is also applied to the $2 \times \mathrm{CO}_{2}$ simulation using the first two PCs. Figure 6(c) shows the corresponding approximate $95 \%$ confidence intervals for the mean when two bivariate Gaussian components are used. The figure shows evidence of a bivariate Gaussian behaviour at the $5 \%$ significance level. Clearly the tendency towards preferred circulation patterns has been reduced in a warmer climate under $\mathrm{CO}_{2}$ doubling.

Figure 7 shows the regime centres of the control simulation within the leading two EOFs along with the covariance matrices of the individual bivariate Gaussians of the mixture. A scatter of $10^{3}$ randomly selected points from PC1 and PC2 are also shown. The anomaly patterns of the regime centres corresponding to the control run (Figure 7) are shown in Figure 8. No such behaviour is obtained with the $2 \times \mathrm{CO}_{2}$ run (Figure 6(c) and Table I). The first anomaly pattern (Figure 8(a)) shows a low pressure centre over the North Pacific and a high pressure centre over the North Atlantic. Note that the low extends up to Greenland. This flow regime is associated with a deepening of the Aleutian low and a northward shift of the North Atlantic jet. The second regime (Figure 8(b)) is nearly the reverse of the first one (Figure 8(a)) and is associated with a weakening of the Aleutian low and a southward shift of the North Atlantic jet.

Extension of the method to more than two PCs is conceptually straightforward. One main technical impediment to this extension is the so-called emptiness

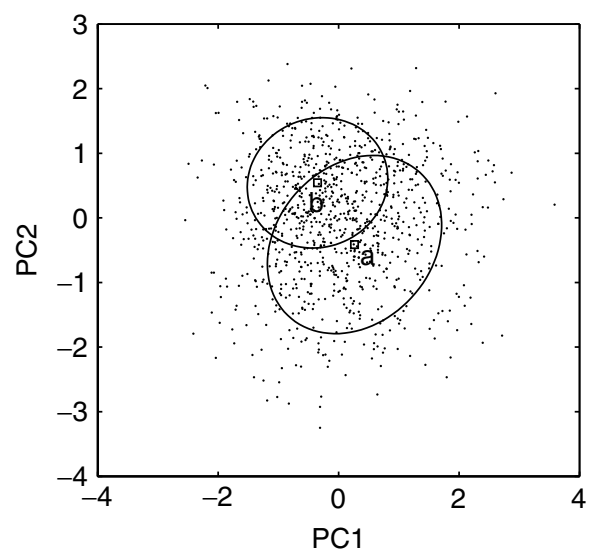

Figure 7. Covariances and centres of the bivariate Gaussians using a two-component mixture model within the leading two surface pressure PCs of the control run. A random subsample of size $10^{3}$ from the PCs is also plotted.
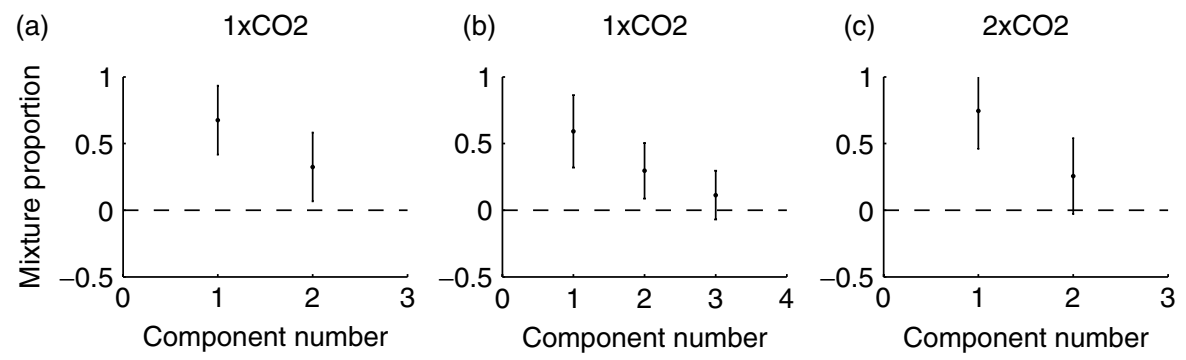

Figure 6. Approximate 95\% confidence intervals of the mixing proportion means in a mixture of (a) two bivariate Gaussians, and (b) three bivariate Gaussians using the leading two principal components of the control $\left(1 \times \mathrm{CO}_{2}\right)$ simulation. (c) is as (a), but for the $2 \times \mathrm{CO}_{2}$ simulation. 
Table I. Number of Gaussian components in the mixture model at different significance levels for the leading two, three, four and five EOFs of the control and doubled $\mathrm{CO}_{2}$ runs.

\begin{tabular}{|c|c|c|c|c|c|c|c|c|}
\hline \multirow[t]{2}{*}{$\begin{array}{l}\text { Significance } \\
\text { level }(\%)\end{array}$} & \multicolumn{4}{|c|}{$\begin{array}{l}\text { Leading EOFs: } \\
\qquad 1 \times \mathrm{CO}_{2}\end{array}$} & \multicolumn{4}{|c|}{$\begin{array}{l}\text { Leading EOFs: } \\
\qquad 2 \times \mathrm{CO}_{2}\end{array}$} \\
\hline & 2 & 3 & 4 & 5 & 2 & 3 & 4 & \\
\hline 5 & 2 & 2 & 2 & 2 & 1 & 1 & 2 & \\
\hline 2.5 & 2 & 2 & 2 & 2 & 1 & 1 & 2 & \\
\hline 1 & 1 & 2 & 2 & 2 & 1 & 1 & 1 & \\
\hline
\end{tabular}

phenomenon in high-dimensional spaces. With the available sample size (9000), one can analyse up to four or five dimensions. To address this point we next extend the method to using only EOFs 1 to 5 . As the state space dimension increases, using the leading three, four or five EOFs the regime behaviour shows up more clearly in the control simulation. Figures 9(a,b) show the 95\% confidence interval for a mixture of two and three Gaussians respectively using the leading four $1 \times \mathrm{CO}_{2} \mathrm{EOFs}$. The two-component model is found to be significant at the $1 \%$ level. No such high significance is obtained for the $2 \times \mathrm{CO}_{2}$ simulation, where regime behaviour is obtained, at the $2.5 \%$ (but not $1 \%$ ) significance level, only when the leading four (Figure 9(c,d)) or five EOFs are used. These results are summarized in Table I, which clearly reflects the decrease in regime behaviour under doubled $\mathrm{CO}_{2}$. Figure 10 shows the centres of the two-component mixture model for the $1 \times \mathrm{CO}_{2}$ (Figure $10(\mathrm{a}, \mathrm{b})$ ) and the $2 \times \mathrm{CO}_{2}$ (Figure $10(\mathrm{c}, \mathrm{d})$ ) runs when the leading four EOFs are used. The patterns obtained using the leading five EOFs are similar to those shown in Figure 10, particularly for the control run, but for the $2 \times \mathrm{CO}_{2}$ run the centres over the North Atlantic become stronger than the associated centres shown in Figure 10. These results are consistent with Table I, reflecting the robustness of the regime behaviour of the control run, compared to the $2 \times \mathrm{CO}_{2}$.

The patterns of the control run are similar to those shown in Figure 8, particularly over the Pacific. In the

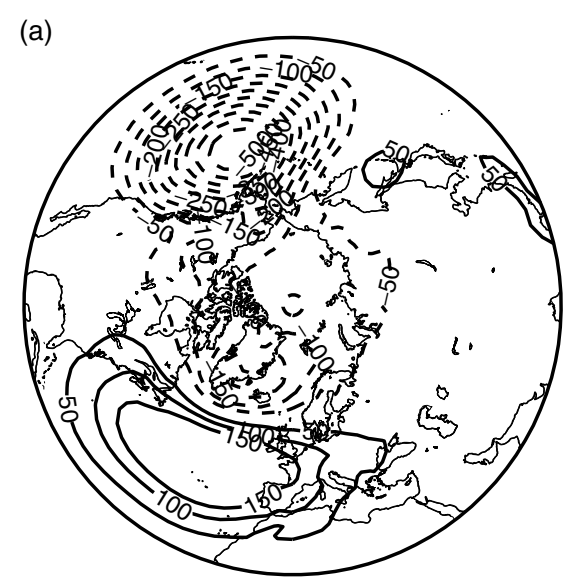

(a)

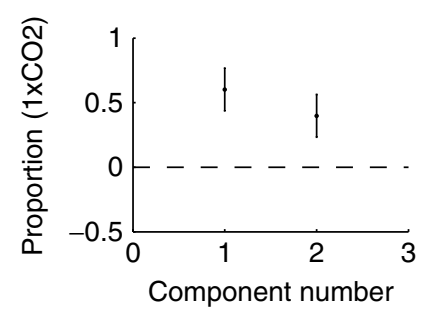

(c)

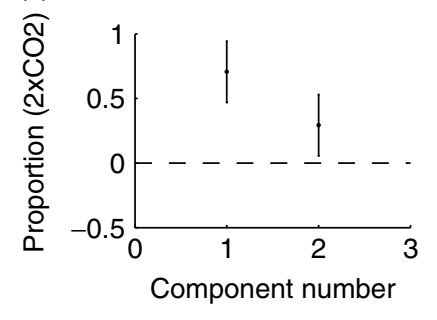

(b)

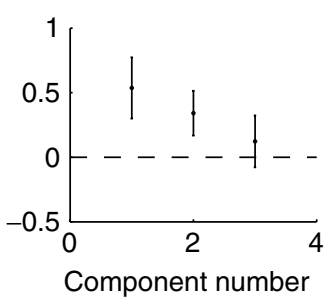

(d)

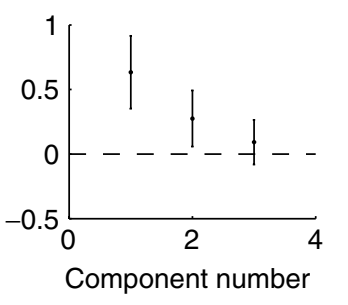

Figure 9. Approximate 95\% confidence intervals of the mixing proportions in a mixture of (a) two, and (b) three bivariate Gaussians using the leading four principal components of the control. (c,d) are as (a,b), but for the $2 \times \mathrm{CO}_{2}$ simulations.

Atlantic sector we have a weak dipole over Eurasia and west of the Iberian peninsula (Figure 10(a,b)). For the doubled $\mathrm{CO}_{2}$ experiment, the Pacific centre is accompanied by a weaker centre over northern Russia and southern Greenland (Figure 10(c,d)). The Pacific low centre of the $2 \times \mathrm{CO}_{2}$ simulation (Figure $10(\mathrm{c})$ ) is much deeper than in Figure 10(a), but the high centre (Figure 10(b)) is stronger than the corresponding centre of Figure $10(\mathrm{~d})$. The frequencies of occurrence of regimes, given by the mixing proportions, have also changed substantially. The probability of occurrence of regime 1 has gone down from 0.55 to 0.28 , and of regime 2 has gone up from 0.45 to 0.72 . In terms of severe weather, this means that it is possible that stronger extremes, but with smaller frequencies, will be observed. Figure 11 shows the difference between the $2 \times \mathrm{CO}_{2}$ and the $1 \times \mathrm{CO}_{2}$ preferred flow patterns. The figure shows, for both patterns, a decrease in the Aleutian low with a stronger decrease for pattern one

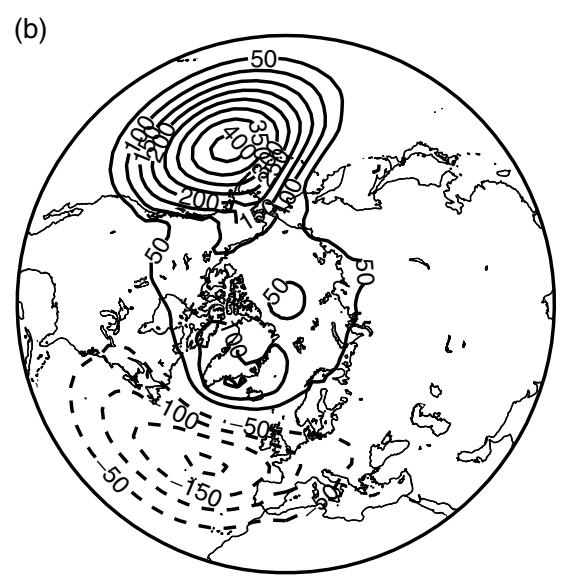

Figure 8. Regime patterns of the control simulation representing the centres of the bivariate Gaussians in a two-component mixture model shown in Figure 7. The contour interval is $50 \mathrm{~Pa}$. 
(a)

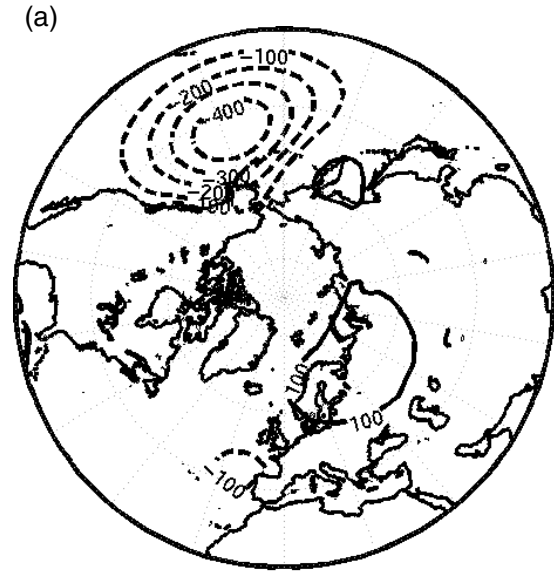

(c)

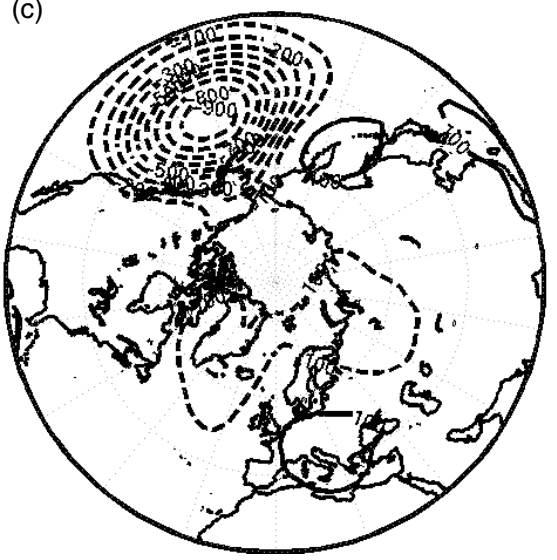

(b)

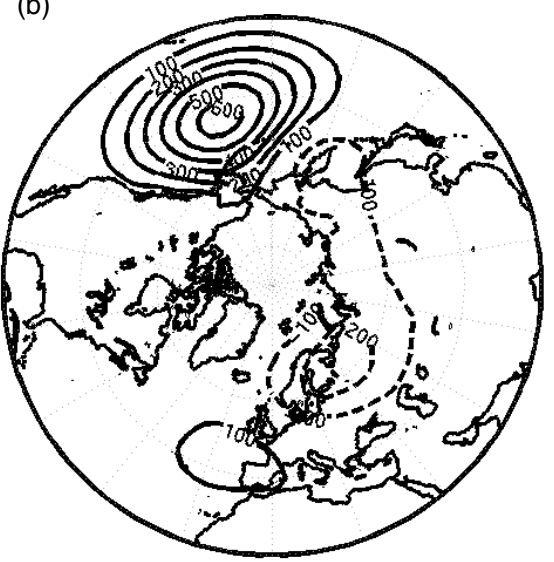

(d)

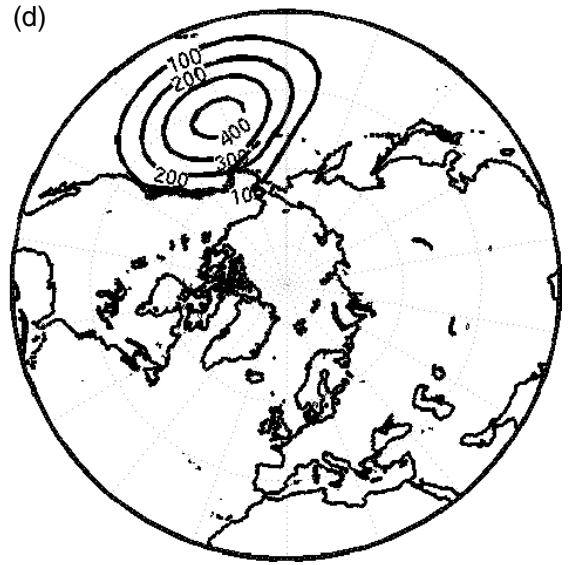

Figure 10. The preferred circulation patterns obtained by fitting a two-component multivariate Gaussian mixture model using the leading four PCs from $(a, b)$ the control and $(c, d)$ the $2 \times \mathrm{CO}_{2}$ simulations. The contour interval is $100 \mathrm{~Pa}$.

(a)

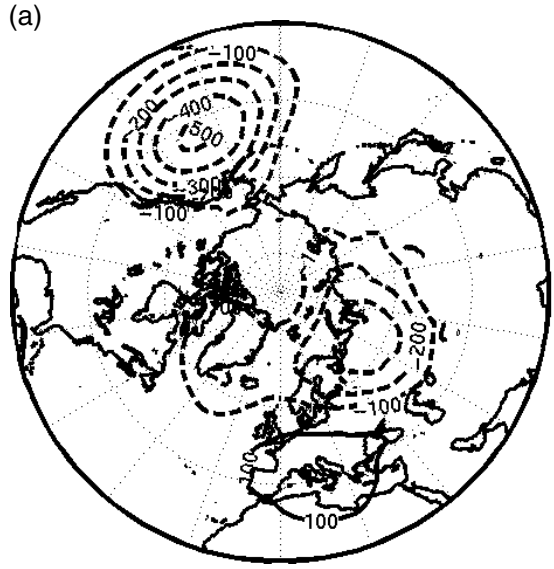

(b)

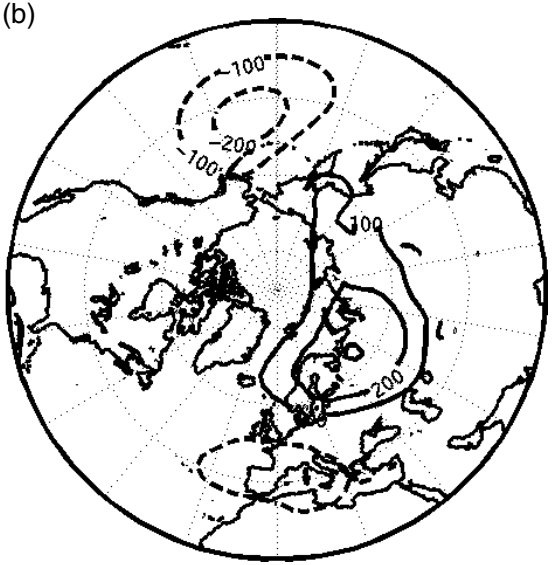

Figure 11. The difference in circulation patterns between the control and the $2 \times \mathrm{CO}_{2}$ simulations shown in Figure 10. (a) is Figure 10 (c) minus 10(a), and (b) is Figure 10(d) minus 10(b). The contour interval is $100 \mathrm{~Pa}$.

reaching $-500 \mathrm{~Pa}$ (Figure 11(a)). A more objective comparison between the flow patterns, obtained by adding the climatology difference (Figure 11) to the patterns shown in Figure 11, indicates that this deepening is still significant. There is also an increase/decrease in SP over the Mediterranean/northern Eurasia respectively for the first circulation pattern (Figure 11(a)) and the reverse for the second one (Figure 11(b)). The former change is consistent with a strengthening and an eastward extension of the NAO, whereas the latter change is consistent with a weakening of the NAO.

To test the robustness of the above results we use another set of basis functions. The next five degenerate EOFs are rotated using the VARIMAX procedure (e.g. Hannachi et al., 2006, 2007). The rotated EOF explaining the maximum amount of variance, noted REOF1, is 
selected. The same thing is applied to the next three degenerate EOFs, i.e. EOFs 8,9 , and 10, and the leading rotated EOF is noted REOF2. The associated time series, noted RPC1 and RPC2, are obtained by projecting the data onto REOF1 and REOF2 respectively. In this way the useful properties of spatial and temporal orthogonality of EOFs/PCs are conserved with the newly obtained REOFs/RPCs. These REOFs have been well reproduced from both halves of the model run. The new extended PC state space is now obtained using PC1, PC2, RPC1, and $\mathrm{RPC} 2$. The same procedure is also applied to the $2 \times \mathrm{CO}_{2}$ simulation, where REOF1 is obtained by rotating EOFs 3 to 6 and selecting the pattern with maximum variance, and REOF2 is simply chosen to be EOF7. The analysis based on the new state space spanned by PC1, PC2, RPC1, and RPC2 yields an identical conclusion to that of Table I. For example, the two-Gaussian components obtained using the three- or four-dimensional new state space are significant at the $1 \%$ level for the $1 \times \mathrm{CO}_{2}$ simulation, but not for the $2 \times \mathrm{CO}_{2}$ run (Table I), which also applies to the new state space.

Figure 12 shows the regimes for the control run (Figure 12(a,b)) and the $2 \times \mathrm{CO}_{2}$ run (Figure $12(\mathrm{c}, \mathrm{d})$ ) when PC1, PC2, RPC3, and RPC4 are used. The patterns are quite similar to those shown in Figure 8. They also compare well with those shown in Figure 10. For pattern 1, the weak centres over northern Eurasia
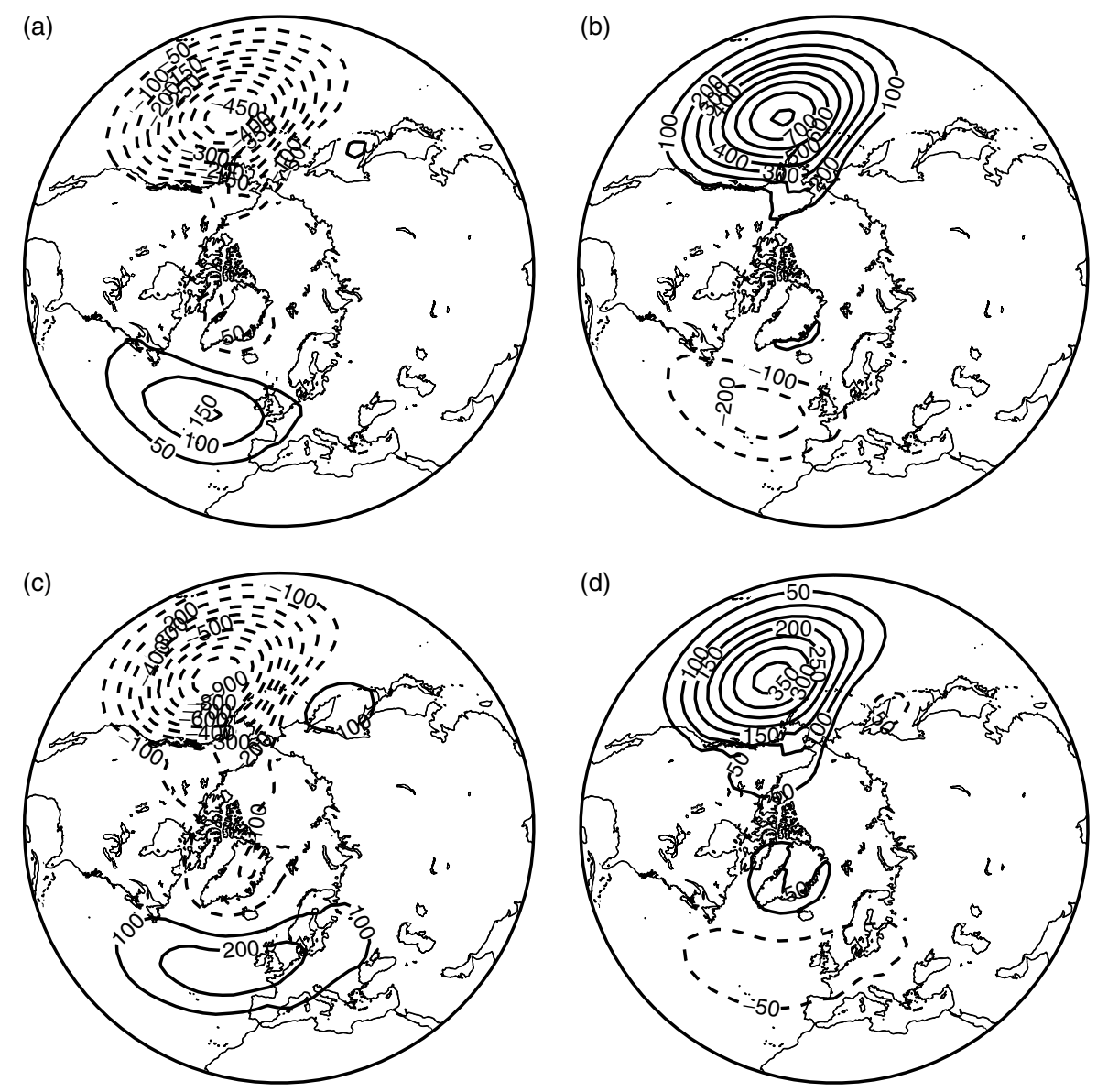

Figure 12. As Figure 10 but using (PC1,PC2,RPC1,RPC2). The contour interval is $50 \mathrm{~Pa}$ in (a,d), and $100 \mathrm{~Pa}$ in (b,c). 
(a)

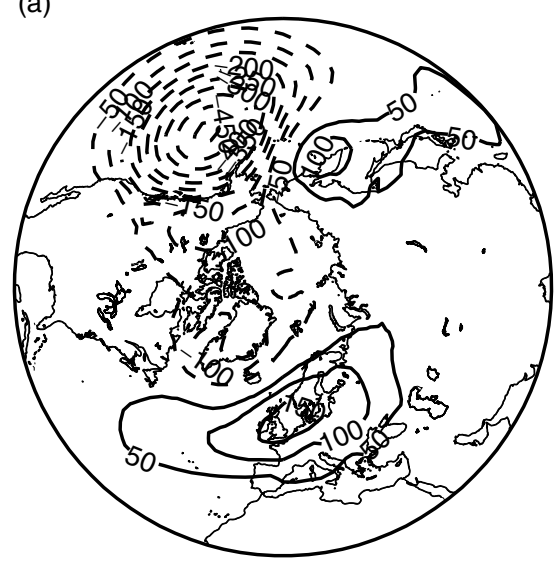

(b)

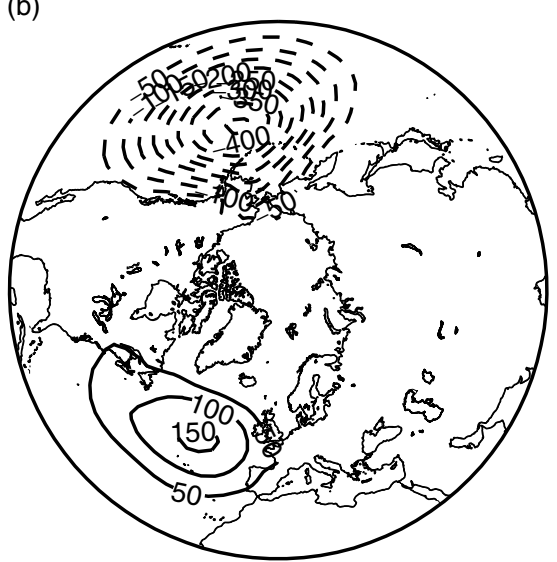

Figure 13. As Figure 11, but using the circulation patterns of Figure 12. The contour interval is $50 \mathrm{~Pa}$.

attracted the interest of climate scientists and has led to a wide scientific debate on the issue of our future climate if this increase continues in the future. Of course, this is a very difficult issue, which can only be tackled via modelling using climate models. In order to reflect the real climate with confidence, a climate model has to simulate and reproduce not only the linear and climatological aspects of climate but also its nonlinear aspect, since the nonlinear aspect plays a non-negligible role in controlling the behaviour of the system on long timescales (although some aspects of climate can be linear on long time-scales).

This paper attempts to address the issue of preferred large-scale flow structure and the effect of changes in greenhouse gas forcing using the Hadley Centre climate model (HadCM3). Changes in preferred structures of planetary-wave dynamics are investigated via searching for evidence in regime behaviour in the surface pressure from two 100-year long simulations. The first, or control, simulation is forced with the pre-industrial level of $\mathrm{CO}_{2}$ concentration and the second, or perturbed, simulation is forced with doubled $\mathrm{CO}_{2}$ concentration. The data used in this investigation consist of daily December-January-February surface pressure north of $20^{\circ} \mathrm{N}$ for each simulation.

The comparison of both the winter climatologies shows that doubled $\mathrm{CO}_{2}$ induces a pressure increase in midlatitudes and the subtropics and a decrease around Newfoundland and the Bering Strait. In terms of climatology, the flow becomes slightly more zonal. Seasonality from the control simulation is also compared to that of the perturbed simulation at three locations: the North Atlantic, the North Pacific and Siberia. Seasonality over Siberia is found to be much weaker than that over the other two locations for both simulations. Overall no shift in seasonality is observed. Under $\mathrm{CO}_{2}$ doubling, over the North Atlantic the median has slightly decreased for most winter months and increased for most summer months, and similarly for the North Pacific.

Next the surface pressure anomalies, with respect to the annual cycle, are area-weighted and EOFs computed. A slight increase in the percentage of explained variance of the first few EOF patterns is obtained for the $2 \times \mathrm{CO}_{2}$ simulation. EOF1 looks more like the NAO in the control simulation and slightly more like the AO in the doubled $\mathrm{CO}_{2}$ simulation. EOF2 shows the Pacific pattern for both runs. The methodology used to study preferred structures follows that of Hannachi (2007), which is based on the multivariate Gaussian mixture model applied to the PCs' state space. At a given significance level, the number of multivariate Gaussian components is obtained using arguments from order statistics.

Using the leading two PCs of the surface pressure anomalies (with respect to the climatology), it is found that the control simulation supports a two-component mixture at the 5\% significance level. Two large-scale flow structures are obtained from these anomalies. They show respectively a high pressure centre over the North Pacific associated with a low pressure centre over the North Atlantic, and its reverse. These structures are also significant at the $2.5 \%$ level. No such behaviour is obtained with the same PCs of the $2 \times \mathrm{CO}_{2}$ simulation at the same significance levels, and the distribution is binormal.

Pattern hunting is next performed using the leading three, four and five EOFs. The circulation patterns from the control run become significant at the $1 \%$ level. For the $2 \times \mathrm{CO}_{2}$ run, the preferred patterns emerge only when the leading four and five EOFs are used, and they are significant at the $2.5 \%$ level but not at the $1 \%$ level. The patterns of the control run are similar to those obtained using the leading two EOFs, particularly over the Pacific with a slight change over the Euro-Atlantic sector. For the $2 \times \mathrm{CO}_{2}$ simulation, the patterns are overall similar to those of the control simulation, particularly over the Aleutians, but with different amplitude. A significant deepening of the Aleutian low is obtained for both regimes. Over the Euro-Atlantic sector, the change is consistent with a strengthening and an eastward shift of the NAO in one case and a weakening of the NAO in the other.

A similar result was obtained using the NCEP/NCAR daily winter $500 \mathrm{mb}$ geopotential heights (Hannachi, 2007) where a change in the frequency of occurrence 
and also the regime patterns was observed between the two periods pre- and post- 1978 . The difference between the regimes of the $2 \times \mathrm{CO}_{2}$ and the $1 \times \mathrm{CO}_{2}$ simulations shows a clear decrease in the North Pacific/Aleutian centre, and a slight increase in the centres over the North Atlantic/Europe, also in agreement with Hannachi (2007). Note that this comparison to the observations is only broad and qualitative since the observed $\mathrm{CO}_{2}$ change over the past 50 years is much less than a doubling.

Based on this particular climate model, the conclusion is that an increase in $\mathrm{CO}_{2}$ greenhouse gas concentration does affect not only the climatology but also other aspects of climate variability. A decrease in large-scale regime behaviour is obtained where the distribution of surface pressure variability gets closer to normality than it would otherwise. The frequency of occurrence of one regime has decreased substantially in favour of an increase in the frequency of occurrence of the other flow regime. The flow patterns also get modified under $\mathrm{CO}_{2}$ doubling where the less frequent regime becomes amplified whereas the other flow regime becomes slightly closer to the climatology. This could also lead to stronger, but less frequent, future extremes.

The different studies conducted on recurrent circulation regimes and the effect of increasing greenhouse gas concentration using climate models seem to show that different models give different results (Kageyama et al., 1999; Hsu and Zwiers, 2001; Solman and Le Treut, 2006). It is true to say that the conducted studies use different approaches. Quantitative evaluation of model differences can only be performed under one single framework using one common methodology, using for example the Climate Models Intercomparison Project (CMIP) under climate change scenarios.

\section{Acknowledgements}

This work was funded by NERC's National Centre for Atmospheric Science (NCAS), the University of Reading. AT was funded via the EU-ENSEMBLES project. Computing resources for running HadCM3 were provided by HPCx. The authors would like to thank Prof. Julia Slingo and two anonymous reviewers for their constructive comments.

\section{References}

Anderson BD, Moore JB. 1979. Optimal Filtering. Prentice Hall: New Jersey.

Christiansen B. 2003. Evidence for nonlinear climate change: Two stratospheric regimes and a regime shift. J. Climate 16: 3681-3690.

Collins M, Tett SFB, Cooper C. 2001. The internal climate variability of HadCM3, a version of the Hadley Centre coupled model without flux adjustment. Clim. Dyn. 17: 61-81.

Corti S, Molteni F, Palmer TN. 1999. Signature of recent climate change in frequencies of natural atmospheric circulation regimes. Nature 398: 799-802.
Cox PM, Betts RA, Bunton CB, Essery RLH, Rowntree PR, Smith J. 1999. The impact of new land surface physics on the GCM simulation of climate and climate sensitivity. Clim. Dyn. 15: $183-203$.

Edwards JM, Slingo A. 1996. Studies with a flexible new radiation code. I: Choosing a configuration for a large-scale model. Q. J. R. Meteorol. Soc. 122: 689-719.

Everitt BS, Hand DJ. 1981. Finite Mixture Distributions. Chapmann and Hall: London, UK.

Gordon C, Cooper C, Senior C, Banks H, Gregory J, Johns T, Mitchell J, Wood R. 2000. The simulation of SST, sea ice extents and heat transports in a coupled model without flux adjustments. Clim. Dyn. 16: $147-168$.

Hannachi A. 2007. Tropospheric planetary wave dynamics and mixture modeling: Two preferred regimes and a regime shift. J. Atmos. Sci. 64: $3521-3541$.

Hannachi A, O’Neill A. 2001. Atmospheric multiple equilibria and non-Gaussian behaviour in model simulations. Q. J. R. Meteorol. Soc. 127: 939-958.

Hannachi A, Jolliffe IT, Stephenson DB, Trendafilov N. 2006. In search of simple structures in climate: Simplifying EOFs. Int. J. Climatol. 26: 7-28.

Hannachi A, Jolliffe IT, Stephenson DB. 2007. Empirical orthogonal functions and related techniques in atmospheric science: A review. Int. J. Climatol. 27: 1119-1152.

Hsu CJ, Zwiers F. 2001. Climate change in recurrent regimes and modes of atmospheric variability. J. Geophys. Res. 106(D17): $20145-20160$.

Inness PM, Slingo JM, Woolnough SJ, Neale RB, Pope VD. 2001. Organization of tropical convection in a GCM with varying vertical resolution; Implications for the simulation of the Madden-Julian oscillation. Clim. Dyn. 17: 777-793.

Kageyama K, D’Andrea F, Ramstein G, Valdes PJ, Vautard R. 1999. Weather regimes in past climate atmospheric general circulation model simulations. Clim. Dyn. 15: 773-793.

Latif M, Sperber K, Arblaster A, Braccanot P, Chen D, Colman A, Cubasch U, Davey M, Delecleuse P, De Witt D, Fairhead L, Flato G, Ji M, Kimoto M, Kitoh A, Knutson T, Le Treut H, Manabe S, Marti O, Mechoso C, Meehl G, Oberhuber J, Power S, Roeckner E, Terray L, Vintzileos A, Vob R, Wang B, Washington W, Yoshikawa I, Yu J-Y, Zebiak S. 2001. ENSIP: the El Niño simulation intercomparison project. Clim. Dyn. 18: 255-276.

North GR, Bell TL, Cahalan RF, Moeng FJ. 1982. Sampling errors in the estimation of empirical orthogonal functions. Mon. Weather Rev 110: 699-706.

Palmer TN. 1993. Extended-range atmospheric prediction and the Lorenz model. Bull. Am. Meteorol. Soc. 74: 49-65.

Palmer TN. 1999. A nonlinear dynamical perspective on climate prediction. J. Climate 12: 575-591.

Panagiotopoulos F, Shahgedanova M, Hannachi A, Stephenson DB. 2005. Observed trends and teleconnections of the Siberian high: A recently declining center of action. J. Climate 18: 1411-1422.

Pope VD, Gallani ML, Rowntree PR, Stratton RA. 2000. The impact of new physical parametrizations in the Hadley Centre climate model: HadAM3. Clim. Dyn. 16: 123-146.

Solman AS, Le Treut H. 2006. Climate change in terms of modes of atmospheric variability and circulation regimes over southern South America. Clim. Dyn. 26: 835-854.

Spencer H, Slingo JM. 2003. The simulation of peak and delayed ENSO teleconnections. J. Climate 16: 1757-1774.

Stephenson DB, Hannachi A, O'Neill A. 2004. On the existence of multiple climate regimes. Q. J. R. Meteorol. Soc. 130: 583-605.

Thompson DWJ, Wallace JM. 1998. The Arctic oscillation signature in wintertime geopotential height and temperature fields. Geophys. Res. Lett. 25: 1297-1300.

Turner AG, Inness PM, Slingo JM. 2005. The role of the basic state in the monsoon-ENSO system and implications for predictability. $Q$. J. R. Meteorol. Soc. 131: 781-804.

Wallace JM, Thompson DWJ. 2002. The Pacific Center of Action of the Northern Hemisphere annular mode: Real or artifact? J. Climate 15: 1987-1991. 